\title{
Creativity In Product Design
}

\section{Mensavi Yvonne ${ }^{1 *}$}

Masters in Environmental Arts Design, School of Fine Arts, Huzhou University, Huzhou, Zhejiang, China

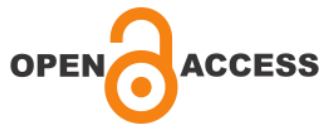

Accepted November 16,2021

Published November 21,2021

*Corresponding Author:

Mensavi Yvonne

DOI :https://doi.org/10.5281/z enodo.5717162

Pages: 124-129

Funding: None

Distributed under

Creative Commons CC BY 4.0

Copyright: (C) The Author(s)

How to cite this article (APA): Yvonne, M. (2021). Creativity In Product Design. North American Academic Research, 4(11), 124129. doi:

https://doi.org/10.5281/zenodo. $\underline{5717162}$

\section{Conflicts of Interest}

There are no conflicts to declare.

\section{ABSTRACT}

The aim of this paper is to examine the close relationship between design and creativity and how they depend on each other. The ability of humans to design has persisted over the years though ways and methods have changed, for the reason that organization, culture and technology have changed as well. From the time of the Stone Age where spears were carved out of woods to hunt animals and stones were sharpened to dig holes till today, creativity and design have persisted. It is argued that even though design is considered an unchanging and unique skill, it has showed itself in diverse ways over time. The production of products and services as well as the creative design process have evolved considerably over time as well. In today's world of business, creativity in design has become so necessary and important. Based on the evaluation of products created by design companies, this paper looks at how creativity can be measured. As a result, it is discovered that for products to be commercially successful and draw the needed attention in the market place, the design should be creative or novel.

Keywords: DESIGN, CREATIVITY, PRODUCT DESIGN, DESIGN THINKING.

\section{Introduction}

In today's global and fiercely competitive economy that keeps evolving rapidly, production companies need to be continuously innovative. For a profitable growth, innovation is now considered as one of the most successful business strategies for increasing market share and it is also a

means of survival. A key factor of enterprise innovation is product innovation whiles creativity is the main factor of product innovation.

\section{What is design?}

Often times when we talk about design, most people think it is the art of making things beautiful but this is not the case. Design is an art as well as science and it involves a lot of calculated processes. Design is a plan or drawing of an object, product or even a system to be developed or produced. According to (Moalosi, Popovic \& Hudson, 2010) design has been in the society and interacting with people a long time ago. Furthermore, national spirit, cultural essence and social value can all be expressed through design. The concepted of design can be traced back to the Stone Age where women and men were farmers and hunters. For the sole purpose of survival, they crafted weapons and tools out of woods, stones, bones and other available materials. However, North American Academic Research, 4(11) | November 2021 | https://doi.org/10.5281/zenodo.5717162 Monthly Journal by TWASP, USA | 124 
their designs were practical and functional unlike modern designs. From the Stone Age till now, design has played a very significant role in our lifestyles. Buildings, cars, electronic gadgets, clothes, shoes and many other things we use are the results of designs that were thought of and brought into existence through creativity.

\section{What is creativity?}

In defining creativity, it is the tendency to recognize or come up with alternatives, ideas, solutions or possibilities that might prove useful in problem solving, communication and even entertainment. According to (Runco,2004), the most important feature in design is creativity. Encouraging the skills to create solutions to problems is another important goal when it comes to disciplines of designs; nevertheless, design is a complicated and to some extent mysterious art that involves "a lot of insubstantial features, for example, creativity, intuition and imagination" (Zeisel,2006,19). Therefore, the creative design process is not so easy to fully comprehend and only partly possible from interpretation through artifacts that were produced for example drawings, paintings and sketches, observations, interviews. Some of the reasons people are motivated or pushed to be creative are:

- The need to develop solutions to problems.

- The need for novelty or uniqueness.

- The need for ideas and values to be communicated.

\section{Objectives}

\section{The objectives of this paper are to:}

- Define what design and creativity is.

- Outline the importance of design creativity or the roles creativity play in product design.

- Outline the ways in which design and creativity are related when it comes to product design.

\section{Literature review}

So far, there has been different definitions of the concept of design. Most of them focused on the term design as an entrepreneurial or economic activity and on the general level, design is seen as a translation of thoughts and ideas generated by being creative thereby producing new processes and products (Bitard and Basset 2008). So far, several attempts have been made to qualify and quantify the main feature of a creative design or idea. To many, they see uniqueness or novelty as the major feature of an idea that is creative. For example, (Newel, Simon and Shaw 1961), proposed that "creativity seem to be a special form of a psychological act that is characterized by novelty". According to (Rhodes 1961), "creativity is seen as a noun that represents the activity where a person develops a new idea or a concept". However, (Davis 2002) argued that, a design idea must be unique as well as have a sense of "social worth, value or appropriateness" for it to be classified creative. (Perkins 2013) also stated that, " by definition, a person that is creative roughly produces results in more or less fields that seem to have both originality and appropriateness". (Amabile and Hennessey 1988) also stated that, "a product must be novel or unique to be considered creative". According to (Lubart and Sternberg 1999), novelty is defined as "not having a likeness to a product that has already been made". To explain further, the North American Academic Research, 4(11) | November 2021 | https://doi.org/10.5281/zenodo.5717162 Monthly Journal by TWASP, USA | 125 
way to determine the creativity or novelty in a product is to compare its features or physical attributes to others of the same kind that are also available at the time of its production. The creativity of the product is then measured based on its different physical attributes when compared to the other existing ones. On the other hand, if there is no other product that has already been produced or designed to solve a problem, then the product or design is truly creative. According to (Chakrabarti \& Bligh, 1994, Westwood \& Sekine, 1988) researchers, managers, product designers, entrepreneurs and other stakeholders that are into the business of developing products need to be novel or creative. Novelty is very important when it comes to the design of products and it also influences a wide range of businesses. (Amabile, 1996; Eder, 1995; Hubka \& Eder, 1996) proposed that Innovation is initiated by novelty or creativity and it also helps in solving a problem and makes it possible for a firm to capture a large space in the market place and keep up with competition. (Ottosson, 1995). (Florida2002) stated that creativity is multi-disciplinary and three different kinds of creativity was identified: inventive or technological creativity, entrepreneurial or economic creativity and cultural or artistic creativity. He then came to the conclusion that there is an interrelation between all these dimensions of creativity because they share the same thinking process and reinforce each other. (DTI, 2005) also defined creativity as the development of new ideas that aim to solve a particular problem in terms of business. In this modern era, design and creativity are closely associated with each other. There is no design without creativity and vice versa. Several researches by other designers have thus far defined the interesting relationship between creativity and design.

\section{Materials and methods}

The research method used in this paper is entirely based on the area, objectives and subject of this study. It was important to apply research methods that support the aim and purpose of the research. Hence, in preparation for this paper based on the subject 'Creativity in Product Design', journals, books, and other reliable sources have been consulted and the method used in this study is the library method with explanations and descriptions. During the writing and completion of this paper, while collecting data from different sources, arrangement and compilation, effort has been put in to properly site the sources of other works.

\section{Discussions}

There is a close relationship between design and creativity because a design is only successful when it has a certain level of creativity. In this case, it can be said that creativity is the reasoning, underlying logic, thinking or idea behind every design ever created. Generally, design can be termed or seen as an economic activity that is made up of lots of other activities. Mostly, the definitions for the term design are actually based on various design professions. Taking for example, product design, fashion design, interior design and graphic design. Creativity is needed in all these design professions. In order for designers, engineers, managers and manufacturers to be creative, they need to be able to see things from different perspectives or in new ways. North American Academic Research, 4(11) | November 2021 | https://doi.org/10.5281/zenodo.5717162 Monthly Journal by TWASP, USA | 126 
Among other things, new possibilities or alternatives need to be generated. When it comes to creativity assessment, not only the number of solutions or alternatives is measured but the uniqueness of those alternatives should be measured as well. The ability to see things in a unique way or generate alternatives as a designer does not happen by change but rather linked to other fundamental thinking qualities. For example, tolerance, patience, flexibility, relaxation, unpredictability or ambiguity and the enjoyment of simple everyday things just to mention a few can serve as sources of inspiration for creativity. Creativity is what make the same product that is designed by different manufacturing companies different in certain ways and therefore unique or novel. For example, cars produced by TESLA and BMW look different even though they perform the same function. For the sake of novelty, it is imperative for designers be creative in the process of developing new products. Advantages of a creativity in product design

- Problems are easily solved: Companies need to develop creative ways and ideas to solve difficult and persistent problems. They need to think outside the box and come up with new ways of doing things. This way, answers are found and problems are easily solved.

- Increase in productivity: By being creative, productive and finding new processes of doing things and productivity is increased tremendously. A designer has to think creatively in order to work smartly. Things that need to be cut off and streamlined have to be identified. New ideas should always be developed and tested as well.

- Creativity serves as a business marketer: Creative innovation and ideas make a business standout from a crowd of many other businesses. Innovation and creativity make people recognize and remember a particular brand or product so it is very crucial for a business to be creative.

- Beat Competitors: It is very easy for a designer or a company that is innovative to beat other competitors. The right amount of creativity helps to come up with better design ideas to create products that will draw and retain the attention of customers. Also, creativity help to identify the appropriate marketing techniques that will make a business successful.

\section{Recommendations}

For design companies to achieve a high level of innovation in their products, instead of rushing to meet the market demand and keep up with competition and end up having similar products like rival companies with little to none novelty, ample time should be put in the design thinking and planning process and not rushed. In this way, the creativity and uniqueness of the product is top notch and the response from the target customers is very high. Product designers should also be open to empathic design where challenges, needs and potential for product design is intuitively understood. A company or designer that combines a deeper knowledge and understanding of how products will be used with the ability to envision new possibilities for that product is an empathic designer. This way, creativity is achieved in the design of products. 
The reconstruction of the product design process with new and creative methods can be very effective in helping designers improve creativity and also increase the total overall performance of innovative product design. Also, efforts must be made to better understand the users' needs. This way, creativity is assured and customers' needs are met accordingly. On the other hand, one factor that affects product creativity in a negative way is the increase in competition. This puts pressure on product designers, engineers and manufacturers to produce new products at a faster speed without taking their time to insure absolute novelty. This usually results in the production of similar goods by other firms that are already on the market. For example, goods like printers, phones, computers and cars by other rival companies in the market place end up looking similar in appearance and function without any distinct or unique features and it becomes extremely difficult for the target customers to appreciate novelty or creativity in these new products. Over the years a lot of researchers across the globe have performed a great deal of researches from varying perspectives such as psychology and inventive problem-solving theories. Nevertheless, the methods they came up with still had limitations for achieving absolute creativity in product design.

\section{References}

1. Moalosi R, Popovic V, Hickling-Hudson A. Culture-orientated product design. International journal of technology and design education. 2010 May;20(2):175-90.

2. Runco MA. Everyone has creative potential.

3. Niculescu MD, Craciunescu CN, Zeisel SH. Dietary choline deficiency alters global and gene-specific DNA methylation in the developing hippocampus of mouse fetal brains. The FASEB Journal. 2006 Jan;20(1):439.

4. Newell A, Simon HA. Computer simulation of human thinking. Science. 1961 Dec 22;134(3495):2011-7.

5. Kampylis PG, Valtanen J. Redefining creativity - analyzing definitions, collocations, and consequences. The Journal of Creative Behavior. 2010 Sep;44(3):191-214.

6. Sternberg RJ, Lubart TI. The concept of creativity: Prospects and paradigms. Handbook of creativity. 1999;1:3-15.

7. Wakkary R, Maestri L. Aspects of everyday design: Resourcefulness, adaptation, and emergence. Intl. Journal of Human-Computer Interaction. 2008 Jun 24;24(5):478-91.

8. Razzouk R, Shute V. What is design thinking and why is it important?. Review of educational research. 2012 Sep;82(3):330-48.

9. Sternberg RJ, Lubart TI. The concept of creativity: Prospects and paradigms. Handbook of creativity. 1999;1:3-15.

10. Sternberg RJ, Lubart TI. The concept of creativity: Prospects and paradigms. Handbook of creativity. 1999;1:3-15. 


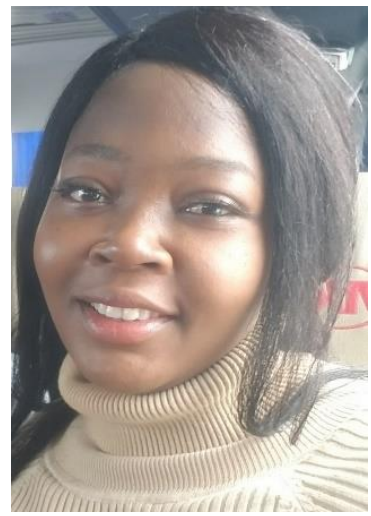

Author's name: Mensavi Yvonne

Email: yvonnemensavi@yahoo.com

(C) 2021 by the authors. Author/authors are fully responsible for the text, figure, data in above pages. This article is an open access article distributed under the terms and conditions of the Creative Commons Attribution (CC BY) license (http://creativecommons.org/licenses/by/4.0/)

Author(s) have identified their affiliated institutions or organizations, along with the corresponding country or geographic region. NAAR, TWASP remains neutral with regard to any jurisdictional claims.

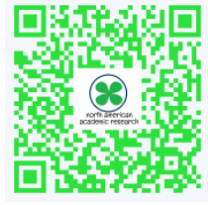

